\title{
Intertextualidade na lei para o controlo de acidentes graves envolvendo substâncias perigosas em Portugal
}

Intertextuality in the Law for the Control of Major-Accidents Involving Dangerous Substances in Portugal

Intertextualité dans la loi de contrôle d'accidents graves impliquant des substances dangereuses au Portugal

\section{Mónica Carvalho}

\section{OpenEdition}

\section{Journals}

Edição electrónica

URL: http://journals.openedition.org/rccs/9028

DOI: $10.4000 /$ rccs. 9028

ISSN: 2182-7435

\section{Editora}

Centro de Estudos Sociais da Universidade de Coimbra

Edição impressa

Data de publição: 1 Setembro 2019

Paginação: 51-74

ISSN: 0254-1106

Refêrencia eletrónica

Mónica Carvalho, «Intertextualidade na lei para o controlo de acidentes graves envolvendo substâncias perigosas em Portugal », Revista Crítica de Ciências Sociais [Online], 119| 2019, colocado online no dia 06 agosto 2019, criado a 08 agosto 2019. URL : http://journals.openedition.org/ rccs/9028; DOl : 10.4000/rccs.9028 


\section{MÓNICA CARVALHO}

\section{Intertextualidade na lei para o controlo de acidentes graves envolvendo substâncias perigosas em Portugal*}

A partir da Análise Crítica do Discurso, examina-se a transposição da Diretiva Seveso III em Portugal, discutindo-se os aspetos mais expressivos da sua intertextualidade discursiva. Esta permite observar tanto a reprodução de discursos - quando nenhum elemento novo é introduzido - como as mudanças discursivas por meio de novas combinações. Entre os principais textos identificados, destacam-se os do universo técnico e económico da gestão corporativa, que são o principal referencial normativo da legislação em análise. Neste artigo discute-se como, através da recontextualização, esses textos exteriores, além de terem a sua própria função normativa no universo onde são produzidos, passam também a ter legalidade segundo as normas da União Europeia e as normas de cada um dos seus Estados-Membros.

Palavras-chave: acidentes químicos; análise crítica do discurso; diretivas internacionais; intertextualidade; prevenção de riscos.

\section{Introdução}

A Diretiva Seveso ${ }^{1}$ surge em 1982 como o primeiro instrumento legal de gestão dos riscos industriais no âmbito da União Europeia (UE), dando uma resposta jurídica e administrativa a dois acidentes industriais graves que ocorreram em dois Estados-Membros nos anos 1970: a explosão na fábrica de químicos de Flixborough, no Reino Unido, em 1974, e o desastre na Industrie Chimiche Meda Società Azionaria em Seveso, Itália, da multinacional Hoffmann-La Roche, em 1976 (Renn, 1989). Desde então,

\footnotetext{
* Este artigo foi desenvolvido com o apoio concedido pela Fundação para a Ciência e a Tecnologia no âmbito da Bolsa de Pós-Doutoramento com a referência SFRH/BPD/99455/2014.

1 "Directiva do Conselho de 24 de Junho de 1982 relativa aos riscos de acidentes graves de certas actividades industriais (82/501/CEE)".
} 
a Diretiva teve duas revisões: em 1996 a Diretiva Seveso II (DSII), ${ }^{2}$ e em 2012 a Diretiva Seveso III (DSIII), ${ }^{3}$ atualmente em vigor.

Sempre que uma diretiva é deliberada no Parlamento Europeu e na Comissão Europeia, cada Estado-Membro da UE tem um prazo para realizar a sua transposição para a própria legislação. Em Portugal, a transposição da DSIII é o Decreto-Lei n. ${ }^{0}$ 150/2015 de 5 de agosto de 2015 (DL 150/2015), ${ }^{4}$ que mantém e reforça a maioria das determinações da DSII.

Embora quatro "novidades" justifiquem a implementação da nova lei, a principal é

[...] a adaptação do anexo I da Diretiva Seveso III, que prevê as categorias de substâncias perigosas, ao sistema de classificação de substâncias e misturas definido pelo Regulamento (CE) n. ${ }^{\circ}$ 1272/2008, do Parlamento Europeu e do Conselho, de 16 de dezembro de 2008. (DL 150/2015, p. 5379)

As três subsequentes, na ordem apresentada no DL 150/2015, envolvem: 1) "o reforço da informação ao púb[1]ico e a definição de um procedimento" para a sua participação na tomada de decisão; 2) "clarificações [quanto] ao ordenamento do território e às inspeções aos estabelecimentos" e 3) alterações administrativas decorrentes da experiência adquirida.

Contudo, se o DL 150/2015 expõe de forma clara os seus propósitos reguladores - pela explicitação e justificação do que se deve manter, reforçar e alterar - como é isto feito? Ou seja, de que modo - nos discursos implícitos e explícitos que fazem parte da legislação - a sua principal razão legal é justificada e como a(s) ordem(s) de discurso que lhe serve (m) de enquadramento torna $(\mathrm{m})$-se índice para a sua normatividade? Tais questões perspetivam o texto legislativo enquanto fenómeno sociocultural. Assim, além de a lei ser uma resposta jurídica e administrativa a uma realidade que supostamente carece dessa resposta, a regulação também oferece os termos a partir dos quais a realidade deve ser observada, estabelecendo as prioridades de ação e os referenciais discursivos considerados válidos. Desse modo, mostrou-se relevante para este estudo uma análise de discurso ao DL 150/2015, através da Análise Crítica do Discurso (CDA, em inglês) de

\footnotetext{
2 "Directiva 96/82/CE, de 9 de Dezembro de 1996, relativa ao controlo dos perigos associados a acidentes graves que envolvem substâncias perigosas".

3 "Diretiva 2012/18/UE do Parlamento Europeu e do Conselho, de 4 de julho de 2012, relativa ao controlo dos perigos associados a acidentes graves que envolvem substâncias perigosas, que altera e subsequentemente revoga a Diretiva 96/82/CE do Conselho".

4 "Decreto-Lei n. ${ }^{\circ}$ 150/2015 de 5 de agosto de 2015. Diário da República n. ${ }^{\circ} 151 / 2015$, Série I de 2015-08-05. Lisboa: Ministério do Ambiente, Ordenamento do Território e Energia”.
} 
Fairclough, em particular pela sua dupla dimensão analítica - envolvendo a parte linguística e a sociocultural, sendo esta uma decorrência da análise intertextual que a CDA propõe.

\section{CDA e intertextualidade}

$\mathrm{Na} \mathrm{CDA}$, tal como em outras escolas, a linguagem é uma parte irredutível da vida em sociedade, o que remete à importância da linguagem para a análise do social. Contudo, se por um lado a CDA afirma que os discursos têm um papel ativo na construção do mundo social, isto não significa que possa ser reduzido apenas à linguagem, no sentido de que tudo seria discurso. Além disso, apesar de a análise textual ser uma etapa significativa na análise do discurso, esta não está restrita à análise linguística dos textos - além de se focar nos textos específicos, a análise do discurso visa o que Fairclough denomina ordem de discurso. Ordem de discurso é a maneira com que diversos géneros, discursos e estilos se interconectam em rede, de modo a constituir uma determinada forma dominante de ordenamento dos sentidos - se algumas maneiras de criar sentido são dominantes ou mainstream numa certa ordem de discurso, outras, pelo contrário, podem ser percebidas como marginais, de oposição ou alternativas (Fairclough, 2003: 206).

Fairclough também ressalta que a CDA se interessa pela continuidade e pela mudança - no sentido abstrato, mas também nos textos em particular. Isto pode ser observado através tanto dos aspetos linguísticos dos textos, como do que o autor chama de análise interdiscursiva - olhar para os textos segundo os diferentes discursos, géneros e estilos que esses textos utilizam e articulam em conjunto (ibidem: 3 ). É no âmbito da análise interdiscursiva que se vão inserir as noções de interdiscursividade e de intertextualidade.

A interdiscursividade ocorre quando diferentes discursos e géneros são articulados em conjunto num mesmo evento comunicativo, ou seja, numa mesma instância de uso da linguagem, i.e., uma matéria de jornal, um filme, um discurso político, um artigo científico, um decreto-lei, etc. Através de novas conexões entre os discursos, as fronteiras mudam, tanto no interior de uma ordem de discurso como entre diferentes ordens de discursos (Jørgensen e Phillips, 2002). Porém, a interdiscursividade também pode ser compreendida como uma forma de intertextualidade (ibidem). O próprio Fairclough (1992) utiliza o termo "intertextualidade" de forma indistinta, significando tanto interdiscursividade como intertextualidade. No entanto, também os diferencia (Fairclough, 2003) ao restringir a intertextualidade a uma "intertextualidade manifesta" - quando há a presença explícita de outros textos num texto - ou quando se refere à interdiscursividade como "intertextualidade constitutiva", enfatizando apenas as convenções 
discursivas - géneros e estilos - e não outros textos. Neste artigo, opta-se pela utilização do termo "intertextualidade" de forma indistinta - ou seja, podendo referir-se tanto à "intertextualidade manifesta" como à "intertextualidade constitutiva" -, embora se aborde mais o aspeto manifesto ou a presença explícita de outros textos no texto analisado do que as convenções discursivas, como os géneros e estilos. ${ }^{5}$

O termo "intertextualidade" foi cunhado por Kristeva (1986), a partir da sua interpretação do dialogismo do Bakhtin (1986). Significa a inserção da história/sociedade num texto e deste texto na história/sociedade. Quando Bakhtin fala de "dois caminhos que se fundem dentro da narrativa" (ibidem: 84; tradução da autora), ele considera a escrita como uma leitura do corpus literário anterior e o texto como uma absorção e uma resposta a outro texto. Assim, qualquer enunciado funciona como um elo numa corrente de comunhão do discurso.

O nosso discurso, isto é, todos os nossos enunciados (incluindo as obras criativas), é preenchido pelas palavras dos outros, graus variados de alteridade ou graus variados de "identidade" [our-own-ness], graus variados de consciência e de distanciamento. Essas palavras dos outros trazem consigo a sua própria expressão, o seu próprio tom avaliativo, que assimilamos, retrabalhamos e re-alçamos. (ibidem: 89; tradução da autora)

Embora Bakhtin tenha aplicado a sua perspectiva dialógica ou intertextual ao estudo dos textos literários, Kristeva ampliou o seu alcance ao afirmar que "qualquer texto é construído como um mosaico de citações; qualquer texto é uma absorção e uma transformação de outro[s]" textos (1986: 37; tradução da autora). É a partir dessa perspetiva, que também podem ser observados como discursos os textos legais em geral, inclusive as legislações, considerando-os tanto pelo aspeto linguístico como através da análise intertextual.

\section{Aplicação da CDA aos textos legislativos}

No âmbito da CDA, há um número restrito de estudos acerca dos textos legais, e mais reduzidos ainda são os estudos que estão especificamente

\footnotetext{
${ }^{5}$ Isto não significa que a "intertextualidade constitutiva", central na construção das legislações, não possa ser considerada no âmbito de uma análise discursiva aos textos legislativos. Contudo, caso se optasse por incluí-la aqui, seria uma escolha fundamentada numa análise mais funcionalista, que está presente nos trabalhos de Bhatia (1998) e Frade (2004), por exemplo, citados neste artigo, o que, no entanto, acabaria por distanciar-se do objetivo aqui proposto, para o qual a CDA parece ser mais pertinente.
} 
voltados para a análise dos textos legislativos ou leis. Segundo afirmam Niemi-Kiesiläinen et al. (2007), a escassez desse tipo de estudos deve-se à persistência de um interesse limitado pela análise do discurso dentro da sociologia do direito, atribuída sobretudo a uma grande influência das diversas formas do funcionalismo estrutural nos estudos desenvolvidos nessa área. Contudo, essas autoras sublinham que nas suas análises aos textos legais, relativos à violência contra a mulher na Finlândia, depararam-se com questões que ultrapassavam os limites da normatividade jurídica, pois envolviam a sua relação com outros sistemas normativos da sociedade (ibidem: 70). Desse modo, através da CDA, Niemi-Kiesiläinen et al. observaram como os valores socioculturais se refletem nos conceitos e nas interpretações das leis, explicando certas relações entre o normativo e o factual, entre a teoria social e a jurídica (ibidem: 69).

Ressaltam-se também os estudos desenvolvidos por Ruth Wodak envolvendo análises de discurso às políticas, embora de forma não restrita aos textos legais (Wodak e van Leeuwen, 1999; Muntigl et al., 2000; Wodak, 2000; Wodak e Weiss, 2005; Wodak e Fairclough, 2010). Desses, sublinha-se o de Wodak e van Leeuwen (1999) que, a partir de uma abordagem interdisciplinar, incluindo a CDA e outras metodologias, analisaram os processos que conectam legitimação e legalidade na produção dos discursos oficiais e não-oficiais sobre imigração na Áustria. O foco foram os problemas que surgiram quando imigrantes fizeram um pedido formal de "reunião familiar" que, embora legal, costuma ser negado, com destaque para a dimensão intertextual e a recontextualização dos discursos.

Ainda Wodak e Fairclough (2010), a partir de duas abordagens diferentes na CDA, também investigaram os processos e relações nas políticas para o ensino superior, a partir da transposição da Declaração de Bolonha em dois Estados-Membros da UE: Roménia e Áustria. O objetivo era perceber os efeitos dos diferentes contextos sociopolíticos e históricos sobre os processos de recontextualização dos documentos políticos, incluindo leis, sobretudo através das "dimensões intertextual e interdiscursiva" (ibidem: 24) dos textos analisados.

A recontextualização é muitas vezes realizada textualmente na mistura de elementos "novos" recontextualizados e de elementos "antigos", como palavras particulares, expressões, argumentos, topoi ${ }^{[6]}{ }^{6]}$ dispositivos retóricos e assim por diante. As tensões,

\footnotetext{
${ }^{6}$ Topoi pode ser descrito como as partes da argumentação que pertencem à categoria das premissas obrigatórias. São as justificações formais ou relativas ao conteúdo ou regras de conclusão que conectam o(s) argumento(s) à conclusão, a pretensão da verdade (Wodak e Fairclough, 2010: 38).
} 
as contradições e as antinomias, às quais a recontextualização dá origem, podem ser identificadas e analisadas textualmente, concentrando-se em tal mistura textual ou hibridez. (Wodak e Fairclough, 2010: 24; tradução da autora)

No que se refere à aplicação da CDA a textos legislativos destaca-se a análise comparativa de Bhatia e Bhatia (2011) a duas leis, inicialmente consideradas semelhantes apenas pela controvérsia que geraram: a USA Patriot Act, uma lei antiterrorismo implementada nos Estados Unidos a seguir ao 11 de Setembro, e o artigo 23 proposto pelo Governo de Hong Kong no âmbito da sua Lei Básica, uma lei antissubversão que tentou implementar, mas sem sucesso até hoje, pois tem sido objeto de intensa desaprovação popular desde 2002. Apesar de se tratar de duas peças legislativas distintas, de contextos políticos diferentes, os autores mostram que ambas as leis servem para legitimar a concentração de "amplos poderes de interpretação e de aplicação nas mãos dos governos e suas instituições executivas" (ibidem: 13; tradução da autora) e a restrição de direitos considerados básicos.

Tesemma (2012) também utilizou a CDA para analisar textos legislativos e documentos oficiais relacionados com a política educacional voltada para pessoas com deficiência na África do Sul. Com sua análise, a autora destacou o anacronismo existente hoje no país entre as leis vigentes e algumas práticas educacionais voltadas para crianças com deficiências.

Frade (2004) analisou, em duas leis, como a recontextualização é realizada por meio da generalidade, indistinção e imprecisão de termos e expressões. O termo recontextualização, contudo, não tem o mesmo significado que em Wodak e van Leeuwen (1999) ou Wodak e Fairclough (2010). Além disso, apesar de vincular a sua abordagem a Bakhtin e Kristeva, Frade (2004) utiliza a noção de intertextualidade com o objetivo de perceber como a informação legislativa alcança a sua intenção comunicativa dentro do sistema legal. Ou seja, Frade não parece ter em vista a mediação entre o social e o discurso (Wodak e Fairclough, 2010) ou a normatividade jurídica e outras normatividades (Niemi-Kiesiläinen et al., 2007). Na verdade, a autora seguiu o referencial funcionalista de Bhatia (1998), que ressalta as diferentes funções dos dispositivos intertextuais no contexto jurídico, em especial para os que são do direito. Isto remete ao que já se referiu anteriormente (Niemi-Kiesiläinen et al., 2007) sobre a persistência, dentro da sociologia do direito, de um interesse ainda limitado na análise do discurso, atribuído sobretudo a uma grande influência das diversas formas do funcionalismo estrutural nos estudos desenvolvidos nessa área. Diferentemente, uma análise intertextual nos termos da CDA inscreve-se metodologicamente como resposta ao postulado bakhtiniano de "ciência translinguística" (Kristeva, 1986: 40). 
[...] a análise linguística mostra como os textos se baseiam seletivamente nos sistemas linguísticos [...], a análise intertextual mostra como os textos se baseiam seletivamente nas ordens de discurso - as configurações particulares das práticas convencionais (géneros, discursos, narrativas, etc.), que estão disponíveis aos produtores e intérpretes de textos em circunstâncias sociais particulares [...]. (Fairclough, 1992: 194; tradução da autora)

$\mathrm{Na}$ "recontextualização intertextual" em Frade (2004), parece escapar o modo como a lei se pauta seletivamente em certas ordens de discurso. Com isto, os aspetos transdisciplinares pertinentes à construção de um texto legislativo ficam de fora, o que não ocorre em alguns dos estudos supracitados (Wodak e van Leeuwen, 1999; Muntigl et al., 2000; Wodak, 2000; Wodak e Weiss, 2005; Niemi-Kiesiläinen et al., 2007; Wodak e Fairclough, 2010). Destaca-se, assim, na análise à lei que aqui se propõe, a importância da intertextualidade a partir do seu papel de mediação entre o texto e o contexto ou entre a linguagem do texto legislativo e o contexto social ao qual pertence, nos termos do que Fairclough descreve acima e não se restringindo à normatividade jurídica.

\section{Intertextualidade no Decreto-Lei n. $^{\circ} 150 / 2015$}

Segundo a UE (EU, 2015), uma diretiva é um dos instrumentos jurídicos disponíveis para a implementação de políticas dentro da União. Apesar de ser um instrumento "flexível", exige que os Estados-Membros cheguem a um determinado resultado, deixando-os livres para escolherem a maneira de o fazer. Na prática, o primeiro passo nesse sentido é a transposição da diretiva, passando-a do contexto da UE para o contexto nacional, de modo a "harmonizá-la" com as leis nacionais de cada Estado-Membro.

A transposição implica: [...] analisar a diretiva, interpretá-la, compreender as suas intenções, os objetivos e os métodos, desconstruindo-a, descartando elementos puramente da UE (como procedimentos de Comissão da UE e acordos de revisão da UE); [...] fazer uma análise do direito nacional ponto por ponto para cada elemento da diretiva e identificar se a obrigação já é respeitada ou se requer novas leis nacionais e, em caso afirmativo, o quê; [...] a construção de textos nacionais dentro do quadro legislativo nacional de acordo com as regras nacionais de elaboração [...] para implementar a política da UE. (Robertson, 2011: 63; tradução da autora)

Enquanto transposição, o DL 150/2015 é um texto semelhante à versão portuguesa da DSIII, em particular certos artigos e anexos. Isto deve-se ao 
aspeto formal relativo aos textos legislativos, que costumam seguir padrões semelhantes de terminologias e de organização, mas também porque é suposto que o texto de uma transposição seja uma contextualização e adaptação do texto original aos critérios legais e institucionais do Estado-Membro da UE para o qual a lei europeia deve ser transposta (Robertson, 2011; EU, 2015).

Um exemplo: os títulos dos três primeiros artigos ("Objeto", "Âmbito de aplicação" e "Definições") da DSIII são idênticos aos três primeiros artigos do DL 150/2015, títulos, aliás, bastante comuns nos textos legislativos tanto na UE como em Portugal. No entanto, o conteúdo desses artigos não é igual, pois é adaptado e contextualizado, tal como é suposto numa transposição. Assim, o artigo 1. ${ }^{\circ}$ da DSIII - "Objeto" - diz:

A presente diretiva estabelece normas com vista à prevenção de acidentes graves que envolvem substâncias perigosas e à limitação das suas consequências para a saúde humana e para o ambiente, a fim de assegurar, de maneira coerente e eficaz, um nível de proteção elevado em toda a União. (p. L 197/5)

O mesmo artigo do DL 150/2015 afirma:

O presente decreto-lei estabelece o regime de prevenção de acidentes graves que envolvem substâncias perigosas e de limitação das suas consequências para a saúde humana e para o ambiente, transpondo para a ordem jurídica interna a Diretiva n. ${ }^{\circ}$ 2012/18/UE, do Parlamento Europeu e do Conselho, de 4 de julho de 2012, relativa ao controlo dos perigos associados a acidentes graves que envolvem substâncias perigosas. (p. 5379)

Embora a descrição acima seja muito semelhante, o modo como é contextualizada, em particular a abrangência do texto, é sensivelmente diferente.

Algo semelhante se faz no artigo 3. "Definições", onde os elementos definidos e listados são os mesmos. Contudo, enquanto na DSIII o critério de ordenamento desses elementos não é claro, no DL 150/2015, a lista surge por ordem alfabética. Além disso, as definições podem apresentar diferenças que, embora subtis, não são uma mera reprodução de um documento para o outro. A título de ilustração, vejam-se as definições de acidente grave e risco apresentadas na Tabela 1. 
TABELA 1 - Comparação das definições de "acidente grave" e "risco"

\begin{tabular}{lll}
\hline & \multicolumn{1}{c}{ Diretiva Seveso III } & \multicolumn{1}{c}{ DL 150/2015 } \\
\hline Definição de acidente & Um acontecimento, & Um acontecimento, \\
grave & como uma emissão, & designadamente uma emissão, \\
um incêndio ou uma explosão, & um incêndio ou uma explosão, \\
de graves proporções, & de graves proporções, \\
& resultante de desenvolvimentos \\
não controlados durante & $\begin{array}{l}\text { resultante de desenvolvimentos } \\
\text { não controlados durante }\end{array}$ \\
& o funcionamento de um & o funcionamento de um \\
& estabelecimento abrangido & estabelecimento abrangido \\
& pela presente diretiva, e que & pelo presente decreto-lei, \\
provoque um perigo grave, & e que provoque um \\
imediato ou retardado, & perigo grave, imediato \\
no interior ou no exterior & ou retardado, para a saúde \\
de um estabelecimento, & humana, no interior ou no \\
para a saúde humana & exterior do estabelecimento, \\
& ou para o ambiente, & ou para o ambiente, \\
& e que envolva uma ou & e que envolva uma ou \\
mais substâncias perigosas. & mais substâncias perigosas. \\
\hline A suscetibilidade da ocorrência & A probabilidade de ocorrência \\
de um efeito específico num & de um efeito específico num \\
determinado período de & determinado período de \\
tempo ou em determinadas & tempo ou em determinadas \\
circunstâncias. & circunstâncias. \\
\hline Definição de risco &
\end{tabular}

Fonte: elaboração da autora.

Os exemplos acima informam-nos de que parte da formalidade descritiva numa lei pode impor alguns limites a uma proposta de análise de discurso, pois há elementos textuais e escolhas discursivas muito próprias ao género de discurso analisado, i.e., as terminologias e construções frasais típicas do universo jurídico. Porém, a análise intertextual que aqui se sugere não pretende observar tais aspetos formais, muito embora eles até possam ser analisados de acordo com outras propostas analíticas já referidas (Bhatia, 1998; Frade, 2004). Assim, ressaltam-se os recursos extrajurídicos presentes no texto legislativo, que, aliás, são bastante comuns nas diretivas europeias (Robertson, 2011). Embora diversas terminologias, definições, anexos, etc. utilizados num texto legislativo possam ser considerados legais pelo simples facto de fazerem parte de uma lei (ibidem), se, por exemplo, olharmos com atenção para o DL 150/2015, à semelhança da própria DSIII que transpõe, trata-se de um documento que apresenta diversos elementos comuns aos textos não-legais, ou seja, de outra(s) área(s) que não a jurídica. 
Esse é o caso do termo "risco" descrito na tabela anterior, praticamente idêntico na DSIII e na DL 150/2015. Embora ao fazer parte de uma lei passe a ser um termo legal, a palavra risco é definida no âmbito de um universo administrativo, mais especificamente segundo as áreas de avaliação e de gestão dos riscos. Ao fazer uma revisão dos desenvolvimentos que ocorreram desde a fundação das áreas de avaliação e gestão dos riscos, Aven (2016) destacou a classificação sugerida no glossário da Society for Risk Analysis (SRA), que distingue: 1) as definições qualitativas gerais de risco, que vão quase sempre atribuir incerteza aos eventos e relacionar as consequências negativas e indesejadas, das 2) descrições ou métricas dos riscos, que servem para julgar acerca da dimensão (tamanho) de um risco. Tais métricas podem incluir cálculos como os de probabilidade, de consequências esperadas (prejuízos, perdas), de períodos de tempo, de tempo de exposição, de magnitude, etc. Os cálculos não são todos aplicados em simultâneo, mas são dispostos consoante a situação ou a circunstância à qual se julga que o cálculo é aplicável. Logo, a partir da distinção da SRA relacionada com o modo como se define risco nas áreas de avaliação e de gestão dos riscos, pode-se, de facto, articular estas áreas com o conceito de risco na DSIII e no DL 150/2015. Porém, de forma mais categórica, ambas as legislações se restringem à dimensão métrica do risco, até porque em nenhum momento a noção de incerteza é referida em ambas - nem mesmo na versão em inglês da DSIII, que costuma ser considerada a versão original que serve de base para as traduções para os outros idiomas oficiais da UE (Robertson, 2011). Além disso, explica Aven:

A adequação dessas métricas/descrições depende da situação. Nenhum desses exemplos [diversas métricas listadas] pode ser visto como risco em si, e a adequabilidade da métrica/descrição pode ser sempre questionada. Por exemplo, as consequências esperadas podem ser informativas para populações numerosas e risco individual, mas não noutras situações. Para uma situação de decisão específica, um conjunto selecionado de métricas deve ser determinado atendendo à necessidade de suporte à decisão. (Aven, 2016: 4; tradução da autora)

De acordo com esta explicação, observa-se que a definição de risco do DL 150/2015 e da DSIII fazem exatamente o que não é considerado o mais adequado no entender de Aven, na medida em que sugere que a métrica do risco seja a definição do risco em si e não uma ferramenta para a sua avaliação. Isto porque, para esse autor, os aspetos qualitativo (que considera a relevância da incerteza) e quantitativo (da métrica como ferramenta que serve para avaliar e decidir) são complementares. 
Aven listou também outras definições de risco, categorizadas segundo um sistema de classificação que criou através de exemplos de trabalhos de outros investigadores, em que essas mesmas definições são utilizadas ou referidas. É assim que o autor identificou nove categorias de definições de risco, entre elas, a categoria que descreve o risco como "probabilidade de um evento (indesejável)" (2012:37; tradução da autora). Nesta categoria, o autor elencou três definições com essa característica, entre as quais a que diz que o risco é a "probabilidade de um efeito específico proveniente de um certo perigo ocorrer num período específico ou em circunstâncias específicas" (ibidem; tradução da autora). Ora, esta definição é bastante semelhante à do DL 150/2015, em que o risco é "a probabilidade de ocorrência de um efeito específico num determinado período de tempo ou em determinadas circunstâncias" (p. 5380). Isto fica mais claro, quando o exemplo com que Aven ilustrou essa definição é um artigo de Kirchsteiger (2002), investigador da Risk Management and Decision Support Unit da Comissão Europeia. Neste artigo, o autor avalia o workshop internacional sobre promoção de harmonização técnica nas tomadas de decisão baseadas no risco. O workshop serviu principalmente para reunir informações sobre diferentes métodos de avaliação dos riscos aplicados às áreas técnicas e nos países da UE, onde, entre outras coisas, se pretendia implementar a Diretiva Seveso II.

Porém, há um detalhe que deve ser sublinhado em relação à definição de risco no DL 150/2015: ao ser recontextualizada $a^{7}$ para a legislação portuguesa, na definição "probabilidade de um efeito específico proveniente de um certo perigo" (Aven, 2012: 37 tradução da autora), a causa do "efeito específico" - que é "proveniente de um certo perigo" - é subtraída da legislação, que a descreve simplesmente como "a probabilidade de ocorrência de um efeito específico" (p. 5380). Dessa forma, o risco, em vez de ser algo que provém de um certo perigo, passa a ser algo que "acontece", ou seja, ocorre uma nominalização, que é quando se descrevem "coisas que acontecem, em vez de coisas que são os efeitos de agentes causais" (Fairclough, 2003: 144; tradução da autora).

A nominalização [...] envolve a 'perda' de certos elementos semânticos das orações - como temporalidade (assim 'destruição' pode encobrir 'foi destruído', 'é destruído', 'será destruído', etc.) e modalidade (logo distinções entre 'é', 'pode ser', 'deveria ser' e assim por diante são 'perdidas'). Isso também pode envolver a exclusão dos Participantes nas orações - assim, neste caso, nenhum dos substantivos ou nominalizações do processo possui um agente (o que seria mais comumente o sujeito

\footnotetext{
${ }^{7}$ Explica-se adiante nesta secção e na Tabela 2.
} 
gramatical de uma oração). [...] não há especificação de quem dá continuidade, age, destrói ou provoca. A nominalização é um recurso para generalizar, para abstrair eventos particulares e séries ou conjuntos de eventos e, nesse sentido, é um recurso irredutível no discurso científico e técnico [...], bem como no discurso governamental [...]. Como observei acima, tal generalização e abstração, por exemplo nos géneros de governança, podem apagar ou mesmo suprimir a diferença. Também pode ofuscar a agência e, portanto, a responsabilidade e as divisões sociais. (ibidem: 143-144; tradução da autora; itálico no original)

Para fazer uma análise intertextual, Fairclough (2003) sugeriu que se observassem os textos ou as vozes incluídas e excluídas, assim como as suas ausências significativas - o que poderia estar presente, mas não está. Assim, na definição de risco apresentada no DL 150/2015, tal como na DSIII, observa-se um processo de dupla exclusão. A primeira exclusão é identificada através da definição de risco "probabilidade de um efeito específico proveniente de um certo perigo ocorrer num período específico ou em circunstâncias específicas" (Aven, 2012: 37; tradução da autora), baseada no já citado artigo de Kirchsteiger (2002). Nesta definição, é excluído o agente que produz o perigo, atribuído como causa. Contudo, uma nova exclusão acontece na definição de risco na legislação portuguesa (DL 150/2015): "a probabilidade de ocorrência de um efeito específico num determinado período de tempo ou em determinadas circunstâncias". Nesta, para além do agente, fica de fora também o perigo, que antes havia sido atribuído como causa-sem-agente do risco, em Kirchsteiger (2002) e Aven (2012).

Além dessa dupla exclusão que faz parte da construção do conceito de risco segundo a lei, pode-se observar a ausência significativa da noção de incerteza. Embora não haja referências textuais à incerteza, esta noção é implícita ao conceito de probabilidade, "considerada uma medida para representar ou expressar a incerteza, obedecendo as regras da probabilidade" (ibidem: 37; tradução da autora). Porém, a incerteza também é pertinente à definição qualitativa de risco, que é própria do universo da avaliação e da gestão do risco; definição esta que não pode ser confundida com a sua métrica, de carácter probabilístico, que costuma ser utilizada como ferramenta para a sua avaliação e tomada de decisão (Aven, 2016: 4).

As exclusões caracterizam-se pela supressão - i.e., algo que não está mesmo no texto - e pelo backgrounding - i.e., algo que é mencionado no texto, mas que precisa ser deduzido a partir de outras referências do texto (Fairclough, 2003). Logo, as exclusões são identificadas pelos processos que levaram à construção da definição de risco na legislação e o backgrounding é a incerteza, ausência que pode ser inferida a partir da noção de probabilidade que faz parte da definição de risco. 
Essas exclusões dão-se a partir de um processo denominado recontextualização. Conceito originalmente desenvolvido por Bernstein, nos anos 1990, no âmbito da sociologia da educação, a recontextualização pode ser operacionalizada na análise do discurso, particularmente quando um discurso se apropria de outros discursos de modo a trazê-los para uma relação especial entre eles para fins de seleção, transmissão e aquisição (Bernstein apud Wodak e Fairclough, 2010: 23). Na definição de risco em análise, a recontextualização dá-se não apenas pela exclusão dos agentes causais, como já se viu, mas também pela conversão da definição "primeira" de risco (Aven, 2012) em três definições distintas no DL 150/2015: risco, perigo e substância perigosa. Ou seja, o risco enquanto "probabilidade de um efeito específico proveniente de um certo perigo ocorrer num período específico ou em circunstâncias específicas" (ibidem, 37) é desarticulado no DL 150/2015, dando origem a risco, perigo e substância perigosa, da seguinte forma:

TABELA 2 - Recontextualização da definição de risco

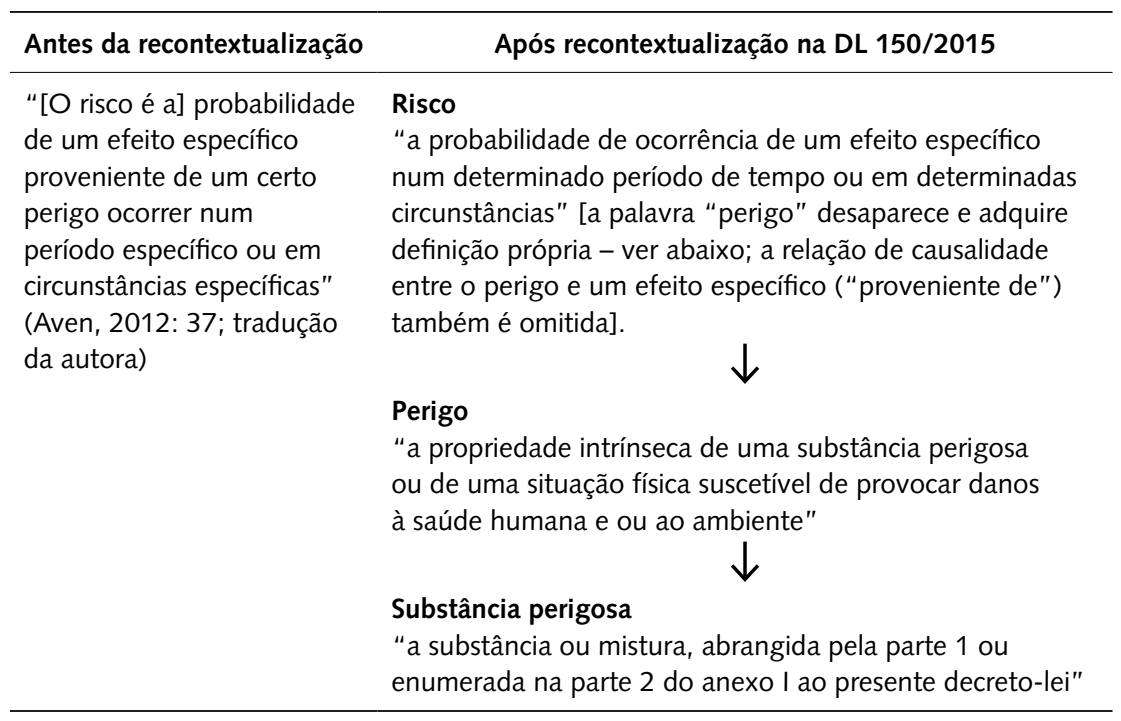

Fonte: Elaboração da autora.

Como a Tabela 2 sugere, a recontextualização do conceito de risco para o DL 150/2015 possibilita uma radical exclusão do elemento causal do universo da gestão dos riscos, uma vez que a definição "primeira" (Aven, 2012) também já carecia de agente. Além disso, ao mesmo tempo que a causalidade é eliminada, a legislação confere valor positivo àquilo que, 
com muita frequência, teria mais facilmente uma conotação negativa, ou seja, as definições de risco e perigo. No mapeamento histórico e conceitual que o próprio Aven (2012) fez sobre o risco no âmbito da gestão do risco, é muito comum a associação do termo à perda, ao que é indesejável ou inconveniente, ao dano e à injúria. Logo, como é possível atribuir valor positivo ao risco e ao perigo quando se afirma que o DL 150/2015 (pp. 5378-5379) "veio prever regras para a prevenção de acidentes graves que envolvam substâncias perigosas e para a limitação das suas consequências para o homem e para o ambiente"?

O termo "perigo" utilizado na definição do DL 150/2015 é a tradução de bazard e não de danger e isto pode ser verificado tanto em Aven (2012:37) como na DSIII em inglês. Hazard é um substantivo que costuma ser empregado para indicar os perigos vistos como fontes potenciais causadoras de danos, sendo, portanto, mais circunscritos e definidos. Está relacionado com a possibilidade de haver prejuízo ou dano para algo ou alguém, i.e., "as viagens espaciais estão cheias de perigos", sendo "viagens espaciais" a fonte mesma do perigo. A questão aqui não é que uma legislação deve emular as definições dos dicionários ou seguir os critérios lexicais clássi$\cos$ - inclusive porque os léxicos costumam apresentar diversas definições e sinónimos popularmente empregues. Contudo, a definição de perigo (hazard) no DL 150/2015, sugere uma mudança no emprego da palavra "perigo", de um substantivo para um adjetivo. Assim, "perigo" (hazard), um substantivo tanto em português como em inglês - a certain hazard ou um certo perigo (Aven, 2012:37) - passa a ser definido como propriedade, ou seja, qualidade ou característica (adjetivo) de uma substância que é qualificada como perigosa ou de uma situação física suscetível de prejudicar as pessoas e o ambiente.

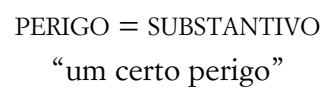

(Aven, 2012: 37)

\author{
PERIGO $=$ ADJETIVO \\ "propriedade intrínseca \\ de uma substância perigosa”
}

(DL 150/2015)

$\mathrm{Na}$ medida em que é compreendido como propriedade intrínseca de uma substância ou de uma situação, o perigo deixa de ser um evento envolvendo pessoas que fazem coisas ou coisas que podem acontecer às pessoas e ao ambiente por se lidar com substâncias perigosas. Na definição de perigo proposta pela DSIII e reproduzida na sua transposição em Portugal, por duas vezes se utiliza a metáfora gramatical, que é quando um significado é interpretado de maneira diferente por meio de uma construção gramatical 
distinta (Fairclough, 2003). Primeiramente acontece uma nominalização, pelo que um processo complexo (em torno de um evento) ou da possibilidade de este existir fica reduzido ao evento ou "ocorrência" do perigo.

À nominalização, segue-se a mudança da função morfológica de um termo - o que era um nome que representava um evento ou "ocorrência", torna-se uma propriedade ou qualidade desse evento, tornando o substantivo num adjetivo, "ofuscando a agência", como referiu Fairclough (ibidem: 144).

O percurso que conduz à definição de substância perigosa talvez seja o mais intricado. Isto porque vai passar pelo rastreio dos intertextos que levam o objeto definido a ser observado pelo seu valor - valor monetário, sobretudo-, o que vai caracterizar positivamente "risco" e "perigo". Assim, no DL 150/2015, substância perigosa é "a substância ou mistura, abrangida pela parte 1 ou enumerada na parte 2 do anexo I ao presente decreto-lei". Esta definição liga-se diretamente à principal razão de ser do próprio DL 150/2015, apresentada na sua introdução e que é:

a adaptação do anexo I da Diretiva Seveso III, que prevê as categorias de substâncias perigosas, ao sistema de classificação de substâncias e misturas definido pelo Regulamento (CE) n. ${ }^{\circ}$ 1272/2008, do Parlamento Europeu e do Conselho, de 16 de dezembro de 2008. (p. 5379)

No entanto, de forma menos evidente que na introdução do DL 150/2015 acima, o Anexo I também é o lugar onde algumas vozes excluídas podem ser identificadas. Uma delas é a da ciência. Se, por um lado, os termos que se relacionam com o universo científico (ciência, científico, cientistas, perito, perícia...) estão ausentes do DL 150/2015, a ciência não está de facto ausente do discurso legal. Sua presença é legitimada por meio de algumas das definições técnicas que fazem parte da lista de definições no artigo $3 .{ }^{\circ}$ - tal como a de risco, por exemplo -, mas, sobretudo, através desse Anexo I.

O Anexo I, "Disposições técnicas relativas às substâncias perigosas", divide-se em: Parte 1 - Categorias de substâncias perigosas; Parte 2 Substâncias perigosas designadas; e Notas ao Anexo I. A Parte 1 abrange todas as substâncias perigosas incluídas nas categorias de perigo, a saber: "Secção 'H' - Perigos para a saúde"; "Secção 'P' - Perigos físicos"; "Secção 'E' - Perigos para o ambiente" e "Secção 'O' - Outros perigos”. Cada uma dessas categorias de perigos compreende outras subcategorias, por exemplo, a "Secção 'H' - Perigos para a saúde" inclui: H1 Toxicidade aguda, categoria 1, todas as vias de exposição; H2 Toxicidade aguda; e H3 Toxicidade para órgãos-alvo específicos. Para cada um desses perigos, correspondem quantidades-limiar (em toneladas) das substâncias perigosas 
referidas na alínea s) do artigo $3 .^{\circ}$, para a aplicação de requisitos de nível inferior e superior (de perigosidade). A Parte 2 é uma lista das substâncias perigosas com os seus respetivos números $\mathrm{CAS}^{8}$ e as quantidades-limiar (toneladas) para a aplicação de requisitos de nível inferior e de nível superior de perigosidade. ${ }^{9}$

Segundo referência anterior do DL 150/2015, o conteúdo do Anexo I é atribuído "ao sistema de classificação de substâncias e misturas definido pelo Regulamento (CE) n. ${ }^{\circ} 1272 / 2008$ " (p. 5379), um documento com quase 2000 páginas do Parlamento Europeu e do Conselho, publicado a 16 de dezembro de $2008 .{ }^{10}$ É apenas neste documento que será indicada a referência original em que se baseia a lista que consta no Anexo 1. Isto fica mais claro quando se menciona nos considerandos do Regulamento 1272/2008 (p. 2) que foi no âmbito da Organização das Nações Unidas (ONU) que se desenvolveram os "critérios harmonizados de classificação e rotulagem que levaram ao Sistema Mundial Harmonizado de Classificação e Rotulagem de Produtos Químicos (a seguir designado 'GHS' [Globally Harmonized System of Classification and Labelling of Chemicals])", critérios esses "internacionalmente acordados".

Assim, fica-se a saber que o GHS, referido no Regulamento 1272/2008, é o ponto de partida para: 1) as tabelas com as categorias de substâncias perigosas no Regulamento 1272/2008; 2) as informações que constam nas tabelas do Anexo I da DSIII e 3) as tabelas das partes 1 e 2 do Anexo I do DL 150/2015.

A ONU é mencionada em dois lugares ao longo do DL 150/2015. O primeiro é nas Notas ao já referido Anexo I, em que se remete o leitor para o documento "Recomendações das Nações Unidas sobre o Transporte de Mercadorias Perigosas: Manual de Ensaios e Critérios" (DL 150/2015, p. 5398). O segundo momento é na parte 2 do Anexo VI "Informação a comunicar ao público", quando é mencionada a Convenção da Comissão Económica para a Europa das Nações Unidas sobre os Efeitos Transfronteiriços de Acidentes Industriais, que abrange a possibilidade de ocorrência de um acidente grave com efeitos transfronteiriços. Contudo, a partir dessas duas referências à $\mathrm{ONU}$, não se consegue inferir uma

\footnotetext{
${ }^{8}$ Os números de registro CAS fornecem um identificador único e inconfundível para substâncias químicas. São usados em muitas outras bases de dados públicas e privadas. Fonte: http://www.cas.org.

9 Segundo a classificação das indústrias abrangidas pela DSIII, as instalações podem ser classificadas como de nível inferior ou superior de perigosidade.

${ }^{10}$ Consultado a 23.03.2017, em https://eur-lex.europa.eu/LexUriServ/LexUriServ.do?uri= CONSLEG:2008R1272:20110419:PT:PDF.
} 
relação clara entre o DL 150/2015 e o sistema GHS da ONU, ou melhor, da Comissão Económica das Nações Unidas para a Europa (UNECE, em inglês).

[O GHS] aborda a classificação de produtos químicos por tipos de perigo e propõe elementos de comunicação de risco harmonizados, incluindo rótulos e folhas de dados de segurança. O objetivo é garantir que a informação sobre os perigos físicos e a toxicidade dos produtos químicos esteja disponível para melhorar a proteção da saúde humana e do meio ambiente durante o manuseio, transporte e uso desses produtos químicos. O GHS também fornece uma base para a harmonização das regras e regulamentos sobre produtos químicos ao nível nacional, regional e mundial, um fator importante também para facilitar as relações comerciais. ${ }^{11}$

Assim, para dar uma consistência ou coerência aos diversos sistemas regulatórios existentes, e seguindo os termos estabelecidos no capítulo 19 da Agenda 21, adotada em 1992 durante a Conferência do Rio de Janeiro ou Eco-92, ${ }^{12}$ a ONU desenvolveu métodos e ferramentas para promover a "harmonização" dos critérios de classificação das potenciais fontes de danos ( hazards) e de comunicação sobre tais fontes. Desenvolvido por uma comissão de peritos, o GHS torna-se a base da "principal alteração" da DSIII e da sua transposição para a lei portuguesa.

Para garantir a consistência entre todos esses sistemas de regulação, as Nações Unidas desenvolveram mecanismos para a harmonização de critérios de classificação de perigos e ferramentas de comunicação de perigo (GHS), bem como para as condições de transporte para todos os modos de transporte (TDG). Além disso, a UNECE administra acordos regionais que asseguram a implementação efetiva desses mecanismos no que diz respeito ao transporte de mercadorias perigosas por via rodoviária, ferroviária e fluvial. ${ }^{13}$

Desse modo, vê-se que, no processo de elaboração de uma regulação ao nível nacional, embora já se saiba que se trata de uma transposição de uma regulação transnacional, há de facto uma rede de discursos da qual faz parte a transposição em análise. Logo, uma das funções do DL 150/2015 é a composição

\footnotetext{
11 “About the GHS", consultado a 23.03.2017 no site da UNECE em https://www.unece.org/ trans/danger/publi/ghs/ghs_welcome_e.html. Tradução e itálico da autora.

12 "Historical background", consultado a 23.03.2017 no site da UNECE em https://www.unece. org/trans/danger/publi/ghs/histback_e.html. Tradução da autora.

13 "Dangerous Goods", consultado a 23.03.2017 no site da UNECE em https://www.unece.org/ trans/danger/danger.html. Tradução da autora.
} 
de "cenários comunicativos" que facilitem os processos de globalização de mercados e indústrias transnacionais que lidam com o que a UNECE chama de "bens perigosos" (dangerous goods) ou, mais especificamente, o "transporte" desses "bens" - sendo que, no âmbito da UNECE, "transporte" é uma área na qual se inclui a comunicação, i.e., o GHS é identificado como ferramenta de comunicação dos perigos (bazard communication tool).

Assim, o GHS parece ser de extrema importância, por uma questão de segurança no manuseio e transporte dos químicos, mas também porque facilita as relações comerciais globais em torno dessas substâncias. De facto, pode-se imaginar o que significa um sistema único de classificação com letras, números e ícones, que sirva tanto a países do bloco "ocidental" - que utilizam um sistema alfabético comum, o que já facilita a comunicação entre si -, quanto a países como a China, o Japão, a Rússia, a Turquia, etc., que utilizam outros sistemas gráficos, inclusive não-alfabéticos, portanto, à partida incompreensíveis para os primeiros.

No âmbito da intertextualidade, observa-se também o efeito de uma supressão que se destaca na lei portuguesa. O termo "bens perigosos", que está no título da publicação da ONU e que a UNECE cita com frequência nos textos que disponibiliza no seu site, parece estar no centro dessa supressão. Enquanto, no Anexo I da DSIII em inglês,,$^{14}$ o item 9 das notas do anexo diz:

9. Testing for explosive properties of substances and mixtures is only necessary if the screening procedure according to Appendix 6, Part 3 of the UN Recommendations on the Transport of Dangerous Goods, Manual of Tests and Criteria (UN Manual of Tests and Criteria) [...] identifies the substance or mixture as potentially having explosive properties. (L 197/24)

$\mathrm{Na}$ DSIII em português e no DL 150/2015, o mesmo item 9 das notas do Anexo I refere igualmente em ambos:

9. O ensaio das propriedades explosivas das substâncias e misturas apenas é necessário se o procedimento de despistagem que consta do apêndice 6, parte 3, do Manual de ensaios e critérios da ONU [...] identificar a substância ou mistura como tendo potencialmente propriedades explosivas. ${ }^{15}$

\footnotetext{
14 "Directive 2012/18/EU of the European Parliament and of the Council of 4 July 2012 on the control of major-accident hazards involving dangerous substances, amending and subsequently repealing Council Directive 96/82/EC (Text with EEA relevance)". Consultado a 23.03.2017, em https://eur-lex.europa.eu/legal-content/EN/TXT/PDF/?uri=OJ:L:2012:197:FULL\&from=PT. ${ }_{15} \mathrm{Na}$ Diretiva da UE está em L 197/24 e no Decreto-Lei 150/2015 na página 5398 do Diário da República, 1. ${ }^{a}$ série - N. ${ }^{\circ} 151-5$ de agosto de 2015.
} 
Logo, é excluído "UN Recommendations on the Transport of Dangerous Goods", presente no original em inglês, ou a sua tradução. Como é o único lugar na DSIII onde é citado o documento da UNECE, assim como a expressão "dangerous goods" ou "bens perigosos", não se consegue perceber o porquê dessa referência ser eliminada da DSIII em português, em particular por tratar-se do título de uma publicação (UN, 2015 [1999]), que é fundamental para a principal alteração proposta pela DSIII.

A título de ilustração, e para que se perceba que a ausência do nome da publicação da UNECE foi uma escolha desde a tradução portuguesa da DSIII, que se consolidou na sua transposição em Portugal, o mesmo item 9 das notas do Anexo I na DSIII em espanhol, igual à sua transposição em Espanha, cita o documento "Recomendaciones de Naciones Unidas relativas al transporte de mercancías peligrosas". Verifica-se que aí o título da publicação não é retirado, mas sim traduzido, e o que em inglês era "dangerous goods" passa a ser lido como "mercancías peligrosas" (mercadorias perigosas). O termo escolhido pelos espanhóis acaba por refletir aquilo que a expressão "bens perigosos" significa, pois em muito textos em inglês voltados para o mercado global de químicos, estas substâncias também são denominadas "commodity chemicals" (produtos químicos de mercado). ${ }^{16}$ Isto também acontece na transposição da DSIII em França, embora nesta o Anexo I da Diretiva tenha sido organizado de modo diferente e o texto "recommandations des Nations unies relatives au transport de marchandises dangereuses" ${ }^{17}$ tenha sido referido quatro vezes. Tal como em Espanha, "dangerous goods" também é traduzido em França como "marchandises dangereuses" (mercadorias perigosas).

Da mesma forma que goods ou bens, "dangerous goods" ou "bens perigosos" são termos ligados ao âmbito comercial - apesar de no universo jurídico também ser definido como valor/pertences -, no sentido de coisas ou objetos que pertencem a pessoas ou empresas, e que podem ser negociados consoante o seu valor; sofrem, portanto, as oscilações do mercado e as suas cotações variam, despertando o interesse de pessoas e corporações. A particularidade, no caso dessas legislações, é que são bens que, para além do seu valor monetizável, têm como característica a perigosidade, que,

\footnotetext{
${ }_{16}$ No site do ICIS, um provedor de informações de mercado petroquímico, há um serviço que se chama "Chemicals Commodity and Product Finder". Consultado a 04.10.2017, em https://www. icis.com/chemicals/channel-info-finder.

17 "Décret n. ${ }^{\circ} 2014-285$ du 3 mars 2014 modifiant la nomenclature des installations classées pour la protection de l'environnement". Consultado a 04.10.2017, em https://www.legifrance.gouv.fr/ eli/decret/2014/3/3/2014-285/jo/texte.
} 
por sua vez, também é um indicador para a sua própria avaliação no mercado mundial de químicos. ${ }^{18}$

Assim, através do percurso que leva à definição de substâncias perigosas, passamos a saber que são, na realidade, bens perigosos ou mercadorias perigosas. Por outro lado, pelo seu crescente valor de mercado e por serem responsáveis por uma excecional performance das indústrias que lidam com elas, inclusive "superando barreiras regulatórias" (Cao et al., 2015: 7), as substâncias perigosas também representam um tipo de risco que vale a pena correr.

\section{Discussão}

A importância da intertextualidade na análise da legislação remete ao modo como outros discursos, principalmente os exteriores ao universo jurídico, passam a fazer parte do discurso legal. Tais discursos, ao serem incorporados à normatividade jurídica, também adquirem o estatuto de lei.

Como afirma Wodak (apud Fairclough, 2003), o processo de produção dos textos no âmbito da elaboração e implementação das políticas, incluindo legislações, envolve um movimento que segue na direção de um consenso. Isto significa que nesses textos é suposto que não ocorram intertextualizações de vozes conflituantes. Logo, o DL 150/2015 não é um texto que visa à promoção do diálogo ou do entendimento entre vozes díspares. A sua perspetiva parece ser sobretudo a de dar continuidade a um tipo de enquadramento característico das operações empreendidas no âmbito das corporações globais, que lidam diretamente com substâncias perigosas. Essa continuidade estabelece como preceito legal o que, por princípio, é considerado legítimo, sobretudo pelo valor das atividades que giram à volta da vasta aplicação dessas substâncias, cuja finalidade é produzir uma grande quantidade de bens de consumo, que fomentam os atuais mercados globais. Dito de outro modo, a recontextualização de textos próprios à gestão corporativa torna legal a normatividade técnica e económica, ${ }^{19}$ ou o que já é considerado legítimo nos termos da ordem global dos mercados dos bens perigosos.

Wodak e van Leeuwen (1999) também se referiram ao modo como legitimidade e legalidade são conectadas em processos onde a lei não pode ser

\footnotetext{
${ }^{18}$ Destaca-se que o valor desses químicos, objetivamente falando, é algo bastante difícil de quantificar para quem esteja fora do universo do mercado global de químicos. Assim, existem muitos relatórios a respeito desse mercado particularizado, inclusive quanto aos tipos de substâncias e regiões geográficas. Contudo, tais relatórios são de acesso limitado, uma vez que podem chegar a custar 6000 dólares americanos cada. Isto demonstra, em parte, o valor que esses bens perigosos possuem.

${ }^{19}$ Económica de forma análoga ao sentido de economia enquanto "sábio governo" de indivíduos, bens e riquezas no interior de uma família (Foucault, 1998).
} 
aplicada de forma "mecânica", porque é suposto ser interpretada. No caso do DL 150/2015, legitimidade e legalidade conectam-se de modo a tornar mecânico o que já é considerado legítimo extrajuridicamente. Essa legitimidade é prévia à lei e faz-se pela racionalização (van Leeuwen, 2007), i.e., relativa aos fins e usos da ação social institucionalizada - as atividades que giram à volta dos químicos - e/ou a sua validade cognitiva.

Além disso, há uma legitimidade construída a partir de uma avaliação moral (ibidem), em torno de um "bem", implícito na construção da definição de risco, que além de ser proveniente de certos textos sobre avaliação e gestão dos riscos, é pertinente ao processo de recontextualização desses mesmos textos na lei. Tal processo leva à construção de premissas (Fairclough, 2003), que podem ser representadas por equações, a partir das quais também é possível inferir uma implicação lógica de valor em torno de uma característica positiva (benéfica) do risco como algo que compensa:

- risco $=$ métrica $($ do perigo $)$

- perigo $=$ propriedade de uma substância perigosa

- substância perigosa $=$ bem perigoso

Assim, a lei harmoniza o universo corporativo e a governança europeia (EC, 2001) ao criar uma continuidade entre o valor das atividades que lidam com os bens perigosos, que se legitima pela rentabilidade que o mercado mundial em torno desses mesmos bens é capaz de proporcionar, e pela sua legalidade, que se justifica através da "correta" e consensual prevenção/gestão dos riscos existentes. Essa harmonização também se dá pela eliminação da agência em torno desses mesmos riscos, observada tanto na exclusão da causalidade na definição mesma de risco, como pela transformação do perigo numa propriedade de algo que é definido pelo seu valor. Conforme se diz no primeiro parágrafo do DL 150/2015, este estabelece formas administrativas de "prevenção e controlo dos perigos associados" à "ocorrência de acidentes de grande dimensão relacionados com a libertação de substâncias perigosas". Com isso, fica estabelecido que os perigos, os acidentes de grande dimensão e a libertação de substâncias perigosas é que são as "coisas" ou objetos da lei, ficando a priori desassociados dos processos complexos que podem levar à sua ocorrência, processos estes que ficam de fora do escopo da regulação.

\section{Referências bibliográficas}

Aven, Terje (2012), "The Risk Concept - Historical and Recent Development Trends", Reliability Engineering \& System Safety, 99, 33-44.

Aven, Terje (2016), "Risk Assessment and Risk Management: Review of Recent Advances on Their Foundation", European Journal of Operational Research, 253(1), 1-13. 
Bakhtin, Mikhail (1986), "The Problem of Speech Genres”, in Speech Genres and Other Late Essays. Austin: University of Texas Press, 60-102.

Bhatia, Aditi; Bhatia, Vijay K. (2011), "Discursive Illusions in Legislative Discourse: A Socio-Pragmatic Study”, International Journal for the Semiotics of Law, 24(1), 1-19. Bhatia, Vijay K. (1998), "Intertextuality in Legal Discourse", Language Teacher-Kyoto-Jalt, 22, 13-18. Consultado a 05.04.2017, em http://jalt-publications.org/old_tlt/ files/98/nov/bhatia.html.

Cao, Bing; Ezekoye, Obi; Glaschke, Michael (2015), "Chemicals and Capital Markets: Still Going Strong”, McKinsey \& Company, julho. Consultado a 04.10.2017, em https://www.mckinsey.com/industries/chemicals/our-insights/chemicals-andcapital-markets-still-going-strong.

EC - European Commission (2001), European Governance: A White Paper. Luxembourg: Office for Official Publications of the European Communities.

EU - European Union (2015), "European Union Directives. EUR-Lex - 114527”. Consultado a 27.09.2017, em http://eur-lex.europa.eu/legal-content/EN/TXT/?uri= LEGISSUM:114527.

Fairclough, Norman (1992), Discourse and Social Change. Cambridge: Polity Press.

Fairclough, Norman (2003), Analysing Discourse. Textual Analysis for Social Research. London/New York: Routledge.

Foucault, Michel (1998), “A governamentalidade: curso do Collège de France, 1 de fevereiro de 1978”, in Microfísica do poder. Rio de Janeiro: Graal, 277-295. Tradução de Roberto Machado.

Frade, Celina (2004), "Generic Variation across Legislative Writing: A Contrastive Analysis of the UNCITRAL Model Law and Brazil's Arbitration Law”, HERMES Journal of Language and Communication in Business, 17(32), 45-75.

Jørgensen, Marianne W.; Phillips, Louise J. (2002), Discourse Analysis as Theory and Method. London: Sage Publications.

Kirchsteiger, Christian (2002), "Workshop Summary Evaluation and how to Proceed: International Workshop on Promotion of Technical Harmonisation on Risk-Based Decision-Making”, Safety Science, 40(1), 383-395.

Kristeva, Julia (1986), "Word, Dialogue and Novel”, in Toril Moi (org.), The Kristeva Reader. Oxford: Blackwell Publishers, 37-61.

Muntigl, Peter; Weiss, Gilbert; Wodak, Ruth (2000), European Union Discourses on Un/Employment. An Interdisciplinary Approach to Employment Policy-Making and Organizational Change. Amsterdam/Philadelphia: John Benjamins Publishing.

Niemi-Kiesiläinen, Johanna; Honkatukia, Päivi; Ruuskanen, Minna (2007), "Legal Texts as Discourses”, in Åsa Gunnarsson; Eva-Maria Svensson (orgs.), Exploiting the Limits of the Law. Swedish Feminism and the Challenge to Pessimism. London/ /New York: Routledge, 69-88. 
Renn, Ortwin (1989), "Risk Communication at the Community Level: European Lessons from the Seveso Directive”, JAPCA, 39(10), 1301-1308.

Robertson, Colin (2011), "Multilingual Legislation in the European Union. EU and National Legislative-Language Styles and Terminology", Research in Language, 9(1), 51-67.

Tesemma, Shimelis Tsegaye (2012), "A Critical Analysis of Law and Policy on the Education of Disabled Children in South Africa". Tese de Doutoramento em Education Management, apresentada à University of South Africa, Pretoria, South Africa. Consultado a 25.09.2017, em http://hdl.handle.net/10500/8879.

UN - United Nations (2015), UN Recommendations on the Transport of Dangerous Goods-Model Regulations, revisão n. ${ }^{\circ} 19$ [orig. 1999]. Consultado a 05.04.2017, em https://www.unece.org/trans/danger/publi/unrec/rev19/19files_e.html.

van Leeuwen, Theo (2007), "Legitimation in Discourse and Communication”, Discourse \& Communication, 1(1), 91-112.

Wodak, Ruth (2000), "Recontextualization and the Transformation of Meanings: A Critical Discourse Analysis of Decision Making in EU-Meetings about Employment Policies”, in Srikant Sarangi; Malcolm Coulthard (orgs.), Discourse and Social Life. New York: Routledge, 185-206.

Wodak, Ruth; Fairclough, Norman (2010), "Recontextualizing European Higher Education Policies: The Cases of Austria and Romania", Critical Discourse Studies, 7(1), 19-40.

Wodak, Ruth; van Leeuwen, Theo (1999), "Legitimizing Immigration Control:

A Discourse-Historical Analysis”, Discourse Studies, 1(1), 83-119.

Wodak, Ruth; Weiss, Gilbert (2005), “Analyzing European Union Discourses: Theories and Applications”, in Ruth Wodak; Paul Chilton (orgs.), A New Agenda in (Critical) Discourse Analysis. Amsterdam: John Benjamins, 121-133.

Artigo recebido a 20.10.2017

Aprovado para publicação a 01.02.2019

\section{Mónica Carvalho}

Investigadora independente

Contacto: monica.marino@gmail.com

ORCID: https://orcid.org/0000-0002-1725-2517 
Intertextuality in the Law for the Control of Major-Accidents Involving Dangerous Substances in Portugal

By means of Critical Discourse Analysis, the transposition of the Seveso III Directive into Portuguese legislation will be examined through an intertextual analysis, in which the most expressive instances of its discursive intertextuality and re-contextualization will be discussed. Intertextuality, defined as how a text uses elements and discourses from earlier texts, allows us to examine both the reproduction of discourses, when no new elements are introduced, and the discursive changes through new textual combinations. Among the main texts identified, those belonging to the technical and economic domain of corporate management are the main normative reference of the legislation. The analysis argues how these external texts, which have their own normative role in their field of origin, by means of re-contextualization they also increase their value as legislation, according to European Union norms and the laws of each Member State. Keywords: chemical accidents; Critical Discourse Analysis; international directives; intertextuality; prevention of risks.
Intertextualité dans la loi de contrôle d'accidents graves impliquant des substances dangereuses au Portugal Partant de l'Analyse Critique du Discours, nous nous penchons sur la transposition de la Directive Seveso III au Portugal, en débattant des points les plus expressifs de son intertextualité discursive. Celle-ci permet tout autant d'observer la répétition de discours - alors qu'aucun nouvel élément n'est introduit - que les changements discursifs par le biais de nouveaux arrangements. Parmi les principaux textes identifiés, il convient de souligner ceux au caractère technique et économique de la gestion corporative, qui représentent la principale référence normative de la législation en cause. Dans cet article, nous abordons la façon dont, par le biais de la recontextualisation, ces textes extérieurs, en plus du fait qu'ils aient leur propre fonction normative dans l'univers où ils sont produits, acquièrent aussi une légalité selon les normes de l'Union européenne et celles de chacun de ses États membres. Mots-clés: accidents chimiques; Analyse Critique du Discours; directives internationales; intertextualité; prévention de risques. 